\title{
Reliability and validity of the Chinese version of the Psoriasis Disability Index (PDI) in Chinese patients with psoriasis
}

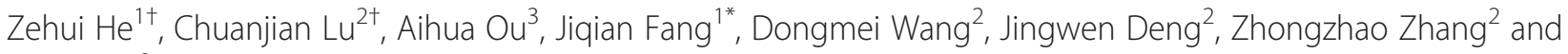
Jingjie $Y u^{2}$

\begin{abstract}
Background: The Psoriasis Disability Index (PDI) is a widely used instrument to measure the impact of psoriasis on patients. There has not been psychometric evaluation of the Chinese version of PDI. The aim of this study was to evaluate its reliability and validity among Chinese patients with psoriasis.

Methods: A multi-center, cross-sectional study was conducted at 9 hospitals including patients aged 18 years and over. Reliability was determined by internal consistency using Cronbach's alpha. Validity was assessed through convergent validity and known groups validity. Dimensionality of the PDI was examined by exploratory factor analysis in working patients and nonworking patients respectively.

Results: In all, 831 patients were studied. Internal consistency of the PDI was satisfactory. Cronbach's alpha coefficient was 0.91 for the total score and over 0.70 for each subscale of the PDI. Evidence of convergent validity of the PDI was proved by excellent and moderate to good correlations with the Dermatology Life Quality Index (DLQI) and four subscales of the Short Form-36 (SF-36) (role-physical, bodily pain, social functioning, and role-emotional): $r=0.51-0.78$. Known groups validity was confirmed that the PDI score discriminated well among patients with different severity of psoriasis. The dimensionality of the PDI was determined by the presence of two-factor structure for working patients and three-factor structure for nonworking patients which accounted for $57.3 \%$ and $62.3 \%$ of the variance respectively.
\end{abstract}

Conclusion: The Chinese version of the PDI is a reliable and valid instrument to assess the impact of psoriasis on patients' lives and could be used in future quality of life assessment of Chinese patients with psoriasis.

Keywords: Psoriasis, Quality of life, Chinese, Psoriasis Disability Index, Exploratory factor analysis

\section{Background}

Psoriasis is a chronic, systemic, and incurable skin condition characterized by the skin signs of thick scaling red plaques with itching and arthritis. It has been proved that psoriasis is associated with risk of cardiovascular disease, diabetes, overweight/obesity and depression [15]. Psoriasis can has profound effects on patients' daily living and functioning [6-8]. While measurements of clinical severity separately using tools such as the Psoriasis Area and Severity Index (PASI) [9] are not sufficient

\footnotetext{
* Correspondence: fangjg@mail.sysu.edu.cn

${ }^{\dagger}$ Equal contributors

'Department of Medical Statistics and Epidemiology, School of Public Health, Sun Yat-sen University, 74 ZhongShan Er Road, Guangzhou, 510080, China Full list of author information is available at the end of the article
}

and may not reflect patients' own perceptions of the impairment due to psoriasis, it is important to assess the impact of psoriasis on patients' physical condition, selfperception, and social life $[10,11]$. Health-Related Quality of Life (HRQOL), covering almost all these parameters, is therefore increasingly part of the clinical research and practice. HRQOL assessment can provide valuable information that helps make clinical decision and select suitable health care programmes $[12,13]$.

There has been a wide variety of generic, dermatology and psoriasis-specific instruments used for the assessment of HRQOL of psoriasis patients [14-18]. However, the reliability and validity of these instruments are not fully known [19-21]. The reliability and validity are the 
major evaluations of instruments' performance of reflecting concepts or ideas such quality of life (QOL) in a study population [22]. Evaluating the characteristics of instruments used to measure patients' perceptions is important in clinical health care and decision making.

The Psoriasis Disability Index (PDI) [15], as a psoriasisspecific instrument, was one of the attempts to measure and quantify the impact of psoriasis on patients' daily lives . It has been used internationally for almost 20 years and has been translated into at least 13 languages [23]. The reliability and validity of the PDI have been evaluated using different languages and in different psoriasis populations. However, the Chinese version of PDI has not been formally validated in Chinese patients with psoriasis. In China, HRQOL research has made a remarkable progress in patient populations [24], but studies on patients with psoriasis at a population level are limited. One of the main reasons is a lack of suitable instruments in Chinese.

In this study, permission was sought and thereby given from the developers of the PDI. Then we used psychometric methods to evaluate the reliability and validity of the Chinese version of PDI in patients with psoriasis.

\section{Materials and methods} Study design and subjects

A multi-center, cross-sectional study of patients with psoriasis in 9 large hospitals was performed from November 2010 to April 2011. For a representative sample of Chinese patients with psoriasis, outpatients and inpatients with psoriasis were recruited consecutively in dermatological clinics of the 9 hospitals located in different geographical regions of China. In the north and south of China, respectively two hospitals participated in the study. In the east and middle of China, respectively one hospital participated in the study. In the west of China, three hospitals participated in the study. Inclusion criteria for this study were: (1) a clinical confirmed psoriasis diagnosis; (2) age 18 years or older; and (3) willingness to provide consent to participate. Patients were excluded if they had a severe mental illness.

After the purpose and the contents of the study had been fully explained to the subjects, written informed consent was obtained. Then all participants were asked to fill out the questionnaires according to their own feelings and opinions. Those who have difficulties in completing questionnaires by themselves finished the questionnaires with the help of trained investigators, who have been trained that every answer should be solely based on participant's own response. Completed questionnaires were collected as soon as they were finished.

This study was approved by the Ethics Committee of the Guangdong Provincial Hospital of Traditional Chinese Medicine.

\section{Measurement tools}

The measurement tools consisted of PDI, Dermatology Life Quality Index (DLQI), Health Survey Short Form (SF-36) and PASI. The DLQI and SF-36 were used to evaluate the convergent validity of the PDI. The PASI, frequently as an assessment of the severity of psoriasis, was used to evaluate the known groups validity of the PDI.

\section{Psoriasis disability index (PDI)}

The PDI, developed by Finlay and Coles, concerns the functional lifestyle disabilities caused by psoriasis [15]. It contains 15 items with 5 subscales: daily activities, work, personal relations, leisure, and treatment. All items are rated on a 4-point scale, with responses of "not at all", "a little", "a lot", and "very much" scored 0, 1, 2, and 3, respectively. Item scores are summed to yield a total score (range: 0-45) with higher score indicating greater limitations experienced because of psoriasis. Particularly, the PDI has a possible 5 work items of which only 3 items need to be responded. Respondents who are working (either full- or part-time) respond to item $6 \mathrm{a}, 7 \mathrm{a}$, and 8 , whereas respondents who are not working respond to items $6 \mathrm{~b}, 7 \mathrm{~b}$, and 8 . When one item of the PDI was not responded, it was scored "0". When two or more items of the PDI were not responded, the questionnaire was excluded from the analysis.

\section{Dermatology life quality index (DLQI)}

The DLQI, developed by Finlay and Khan, assesses the QOL impact of skin disease [14]. Comprising 10 items, the DLQI has been used internationally for more than 15 years and translated into more than 80 international languages $[25,26]$. Each item is scored on a 4-point scale (range $0-3)$. The final score on the questionnaire is the sum of the score of each item (range 0-30). Higher scores indicate worse QOL. Its Chinese version has been evaluated and shown good psychometric properties [27].

\section{Short form-36 (SF-36)}

The SF-36 is a measure of health status and is commonly used in clinical and health services research [28]. Its Chinese version has been tested for psychometric properties [29]. It consists of 8 subscales: physical function (PF), role-physical (RP), body pain (BP), general health $(\mathrm{GH})$, vitality $(\mathrm{VT})$, social functioning $(\mathrm{SF})$, role-emotional (RE), and mental health $(\mathrm{MH})$. The scores of the 8 subscales are calculated according to the scoring algorithm of the SF-36 user's manual. The higher score, the better health. .

\section{Psoriasis area and severity index (PASI)}

The PASI assessed both intensity and extent of the psoriatic plaques separately for four anatomical regions (head, 
trunk, upper and lower extremities) by the physician. The PASI score ranges from 0 (no psoriasis) to 72 (very severe psoriasis), and it was normally regrouped into three categories implying three severity levels of psoriasis: PASI 0-7 (mild severity), PASI 7-12 (moderate severity), and PASI 12-72 (severe severity) [30].

Furthermore, demographic and psoriasis-specific variables such as age, gender, marital status, education, coexisting chronic disease, family history of psoriasis, duration, and clinical type of psoriasis, were reported.

\section{Statistical analysis}

For each subscale of the PDI, the floor and ceiling effects were assessed. If more than $20 \%$ of the patients reported lowest or highest possible score, the floor or ceiling effects exist [31]. Cronbach's alpha and item-total correlations were determined to assess the internal consistency. Construct validity, which hypothesizes a scale measure or correlate with the theorized psychological scientific construct that it purports to measure, was assessed by convergent validity and known groups validity. Convergent validity assessed the degree to which the PDI was similar to (converged on) other measures that it should theoretically be associated to. Spearman's rank correlation coefficient was used to assess correlations between the PDI and the DLQI, the SF-36, which are the two potential measures that assess similar underlying phenomenon as the PDI. Known groups validity tested the ability of the PDI to discriminate between groups that differed in the severity of psoriasis (assessed by PASI). The Kruskal-Wallis test was used to test for statistical differences between the groups. Dimensionality of the PDI was analyzed for patients who were working and not working separately because the work items of the PDI were different for working and nonworking patients. Exploratory factor analysis was used by means of principal component analyses. Oblique rotation (pro$\max$ ) was performed according to the supposed correlations between the factors.

All statistical analysis was performed using SPSS 17.0 (SPSS Inc., Chicago, IL, USA).

\section{Results}

Subjects

In total, 884 patients participated in this study. Out of these, 9 patients were less than 18 years old. Further, 44

Table 1 Demographic and clinical characteristics of the subjects

\begin{tabular}{|c|c|c|c|c|c|c|}
\hline Characteristics & $\begin{array}{c}\text { North } \\
(N=172)\end{array}$ & $\begin{array}{c}\text { South } \\
(N=180)\end{array}$ & $\begin{array}{c}\text { Regions } \\
\text { East } \\
(N=96)\end{array}$ & $\begin{array}{c}\text { West } \\
(N=284)\end{array}$ & $\begin{array}{c}\text { Middle } \\
(N=99)\end{array}$ & $\begin{array}{c}\text { Total } \\
\text { sample } \\
(N=831)\end{array}$ \\
\hline \multicolumn{7}{|l|}{ Gender (\%) } \\
\hline Male & 101(58.7) & 119(66.1) & $55(57.3)$ & 164(57.7) & $74(74.7)$ & $513(61.7)$ \\
\hline Female & $71(41.3)$ & $61(33.9)$ & $41(42.7)$ & $120(42.3)$ & $25(25.3)$ & $318(38.3)$ \\
\hline \multicolumn{7}{|l|}{ Age (\%) } \\
\hline $18-30$ years & 65(37.8) & $61(33.9)$ & $25(26.0)$ & 113(39.8) & $24(24.2)$ & $288(34.7)$ \\
\hline $31-45$ years & $49(28.5)$ & 64(35.6) & $31(32.3)$ & $117(41.2)$ & $46(46.5)$ & $307(36.9)$ \\
\hline $46-60$ years & $44(25.6)$ & $39(21.7)$ & $25(26.0)$ & $35(12.3)$ & $23(23.2)$ & $166(20.0)$ \\
\hline 60 years & $14(8.1)$ & $16(8.9)$ & 15(15.6) & $19(6.7)$ & $6(6.1)$ & $70(8.4)$ \\
\hline \multicolumn{7}{|l|}{ Marital status (\%) } \\
\hline Married or living with partner & $111(64.5)$ & 126(70.0) & $70(72.9)$ & 196(69.0) & $76(76.8)$ & $579(69.7)$ \\
\hline Single & $55(32.0)$ & $50(27.8)$ & $22(22.9)$ & $84(29.6)$ & $22(22.2)$ & 233(28.0) \\
\hline Separated/divorced & $3(1.7)$ & $2(1.1)$ & $4(4.2)$ & $3(1.1)$ & $1(1.0)$ & $13(1.6)$ \\
\hline Widowed & $3(1.7)$ & $2(1.1)$ & $0(0.0)$ & $1(0.4)$ & $0(0.0)$ & $6(0.7)$ \\
\hline \multicolumn{7}{|l|}{ Level of education (\%) } \\
\hline None & $0(0.0)$ & $3(1.7)$ & $1(1.0)$ & $0(0.0)$ & $1(1.0)$ & $5(0.6)$ \\
\hline Primary school & $8(4.6)$ & $13(7.2)$ & $1(1.0)$ & $30(10.6)$ & $3(3.0)$ & $55(6.6)$ \\
\hline Secondary school & $75(43.6)$ & $85(47.2)$ & $40(41.7)$ & 109(38.4) & $36(36.4)$ & $345(41.5)$ \\
\hline College & $83(48.3)$ & $72(40.0)$ & $52(54.2)$ & 139(48.9) & $56(56.6)$ & $402(48.4)$ \\
\hline Higher than college & $6(3.5)$ & $7(3.9)$ & $2(2.1)$ & $6(2.1)$ & $3(3.0)$ & $24(2.9)$ \\
\hline Other chronic disease (\%) & 26.2 & 31.7 & 26.0 & 29.2 & 19.2 & 27.6 \\
\hline Family history of psoriasis (\%) & 25.0 & 22.2 & 26.0 & 19.0 & 26.3 & 22.6 \\
\hline Duration in years mean (SD) & 10.3(11.0) & $8.0(7.0)$ & $11.0(10.0)$ & $8.4(8.8)$ & $11.3(7.1)$ & $9.3(9.0)$ \\
\hline PASI score mean (SD) & $11.0(9.5)$ & $11.0(10.2)$ & $9.8(8.6)$ & $12.0(11.8)$ & $14.0(10.6)$ & 11.6(10.6) \\
\hline
\end{tabular}


patients were excluded because they had two or more missing answers on the PDI. Hence, the analysis was carried out on a total of 831 patients (94\%).

At study inclusion the mean age of patients was 38.6 years $(\mathrm{SD}=13.8)$ and a higher proportion of patients were males than females (62\% vs.38\%).

cardiovascular, musculoskeletal, gastrointestinal, anaphylactic, and gynecological diseases. Twenty-three percent of patients had a family history of psoriasis. The mean duration of psoriasis was 9.3 years $(S D=9.0)$. The most common clinical type of psoriasis was psoriasis vulgaris (92\%), followed by erythrodermic psoriasis (4\%), psoriatic arthritis (3\%), and pustular psoriasis (1\%). The mean severity of psoriasis assessed by PASI was 11.6 (SD $=10.6$ ). Further demographic and clinical characteristics of the patients from different geographical regions are shown in Table 1.

\section{Response distribution}

All subscales of the PDI had small ceiling effects $(<6 \%)$ but mild floor effects (>20\%) for work, personal, and treatment (Table 2).

\section{Reliability}

The means, standard deviations, percentiles, corrected item-total correlations, and Cronbach's alpha coefficients of the PDI and its subscales are presented in Table 2. The subscales of PDI showed Cronbach's alpha coefficients above 0.7 , and the item-total correlation ranged from 0.32 to 0.74 , which suggested an adequate internal consistency of the PDI [32,33].

\section{Convergent validity}

Convergent validity was assessed as satisfactory. The correlations between the total PDI score and the DLQI, SF36 are shown in Table 3. Correlations from 0.25 to 0.50 suggest a fair degree of relation; those from 0.50 to 0.75 are moderate to good; and values greater than 0.75 are considered good to excellent [34]. Results in Table 3 showed excellent correlation between the PDI and the DLQI, moderate to good correlations between the PDI and four subscales of the SF-36 (RP, BP, SF, and RE), and fair correlations between the PDI and the other subscales of the SF-36. There were negative correlation coefficients between the PDI and SF-36 score, because higher PDI score indicated greater functional lifestyle disabilities, whereas higher SF-36 score indicated better health or performance.

\section{Known groups validity}

According to the PASI score assessed by physicians, there were 348 patients (42\%) with PASI $<7,195$ patients (23\%) with PASI $7-12$, and 288 patients (35\%) with PASI $\geq 12$. Therefore, the subjects were divided into three "severity" groups: mild, moderate, and severe. The PDI score showed significantly different among the three groups (Kruskal-Wallis test $\chi^{2}=76.30, \quad P<0.001$ ) and increased with the increasing severity of psoriasis (Figure 1).

\section{Dimensionality of the PDI}

Exploratory factor analysis using an eigenvalue of $>1.0$ as the criterion resulted in two factors for working and three for nonworking subjects (Table 4), which accounted for $57.3 \%$ and $62.3 \%$ of the total PDI variance, respectively. All the 15 items were retained when the criterion of highest loading was used, above 0.40 and at least 0.10 stronger than the next. For working subjects, the first factor may reflect working and social disabilities and the second factor may reflect hygienic disability. For nonworking subjects, the first two factors contained the same items as those for the working subjects but item 14 (More smoke/drink), which was extracted separately as the third factor.

Table 2 Descriptive information and Cronbach's alpha of the PDI total scale and its subscales

\begin{tabular}{|c|c|c|c|c|c|c|c|c|c|c|}
\hline & \multirow{2}{*}{$\begin{array}{l}\text { No. of items } \\
\text { (score range) }\end{array}$} & \multirow[t]{2}{*}{ Mean } & \multirow[t]{2}{*}{ SD } & \multicolumn{3}{|c|}{ Percentile } & \multirow[t]{2}{*}{$\%$ floor } & \multirow[t]{2}{*}{$\%$ ceiling } & \multirow{2}{*}{$\begin{array}{l}\text { Corrected item-total } \\
\text { correlation }\end{array}$} & \multirow[t]{2}{*}{ Cronbach's $a$} \\
\hline & & & & 25 & 50 & 75 & & & & \\
\hline \multicolumn{11}{|l|}{ Chinese version } \\
\hline Daily activities & $5(0-15)$ & 5.3 & 3.5 & 3 & 5 & 8 & 5.2 & 1.7 & $0.58-0.70$ & 0.82 \\
\hline Work & $3(0-9)$ & 2.5 & 2.5 & 0 & 2 & 4 & 27.9 & 4.5 & $0.62-0.72$ & 0.86 \\
\hline Personal & $2(0-6)$ & 1.3 & 1.6 & 0 & 1 & 2 & 30.4 & 4 & $0.64-0.65$ & 0.79 \\
\hline Leisure & $4(0-12)$ & 2.9 & 2.6 & 1 & 2 & 4 & 17.9 & 0.8 & $0.32-0.65$ & 0.74 \\
\hline Treatment & $1(0-3)$ & 0.7 & 0.9 & 0 & 1 & 1 & 34.7 & 5.7 & $-{ }^{a}$ & $-{ }^{a}$ \\
\hline Total & $15(0-45)$ & 12.8 & 9.4 & 6 & 11 & 18 & 3.1 & 0.5 & $0.37-0.74$ & 0.91 \\
\hline \multicolumn{11}{|c|}{ English version $^{b}$} \\
\hline Total score & $15(0-45)$ & 7.3 & 7.2 & 2 & - & 11 & 14.7 & 0 & - & - \\
\hline
\end{tabular}

a Scale consists of one item.

b From a validation study done in the United States [32]. 
Table 3 Spearman's rank correlation coefficients between the total PDI score and the DLQI, SF-36 scores

\begin{tabular}{lcc}
\hline & $\boldsymbol{N}$ & $\boldsymbol{r}_{\boldsymbol{s}}(\boldsymbol{P})$ \\
\hline DLQI & 815 & $0.78^{\mathrm{a}}(<0.001)$ \\
SF-36 & & \\
$\quad$ Physical functioning & 800 & $-0.42^{\mathrm{c}}(<0.001)$ \\
$\quad$ Role-physical & 818 & $-0.58^{\mathrm{b}}(<0.001)$ \\
$\quad$ Bodily pain & 822 & $-0.51^{\mathrm{b}}(<0.001)$ \\
General health & 803 & $-0.34^{\mathrm{c}}(<0.001)$ \\
Vitality & 809 & $-0.40^{\mathrm{c}}(<0.001)$ \\
Social functioning & 814 & $-0.65^{\mathrm{b}}(<0.001)$ \\
Role-emotional & 826 & $-0.58^{\mathrm{b}}(<0.001)$ \\
$\quad$ Mental health & 796 & $-0.45^{\mathrm{c}}(<0.001)$ \\
\hline
\end{tabular}

${ }^{\mathrm{a}}$ Excellent correlation. ${ }^{\mathrm{b}}$ Moderate to good correlation. ${ }^{\mathrm{C}}$ Fair correlation. $N$ : Sample size when correlation was calculated. $r_{s}$ : Spearman's rank correlation coefficients.

\section{Discussion}

As it is increasingly important to assess the impact of psoriasis on the lives of patients, this study adapted an original English and widely used scale PDI to Chinese psoriasis patients. The Chinese version of the PDI was proved to have good reliability and validity by the data presented here.

\section{Response distribution of the PDI}

A moderate percentage of patients were likely to response "Not at all" affected by psoriasis for the work, personal, and treatment subscales of the PDI. Comparing to the large floor effects conducted in a US study (>49\% except daily activities), the floor effects of the Chinese version of PDI were smaller while both ceiling effects were small [32]. The mild floor effects might suggest that some items of the PDI provide limited information on the disabilities caused by psoriasis, especially for those with low level of disabilities and severities.

\section{Reliability and validity of the PDI}

The internal reliability estimated by Cronbach's alpha exceeded 0.7 in the total scale and all subscales of the PDI, which indicated a good reliability of the instrument. Similar results have been found in other language versions of the PDI $[32,35,36]$. Regarding the validity, excellent and moderate to good correlations with the DLQI and certain subscales of the SF-36 added to available evidence of convergent validity for the PDI. The English and Norwegian versions of the PDI have also proved their convergent validity $[32,35]$. The results of known groups comparison indicated the discriminate ability of the PDI was good enough to distinguish the patients with different severities of psoriasis, which was consistent with previous studies [32].

\section{Dimensionality of the PDI}

The items of PDI were grouped into five subscales based on common sense when the PDI was developed [15]. However, the original structure could not be confirmed by factor analysis [37], and no consensus exists regarding the number of factors composing this scale. It has been

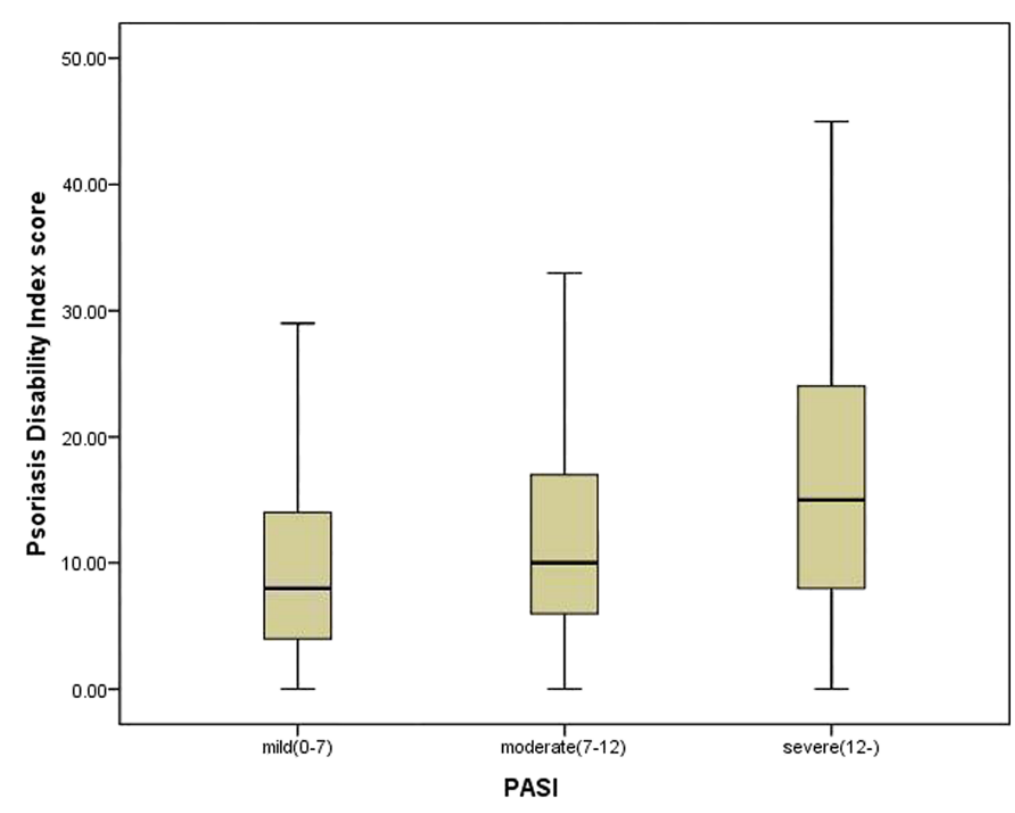

Figure 1 Box plot of the PDI score stratified to severity of psoriasis assessed by the PASI. 
Table 4 Exploratory factor analysis of the PDI

\begin{tabular}{|c|c|c|c|c|c|c|}
\hline \multirow[b]{2}{*}{ Scales } & \multirow[b]{2}{*}{ Items } & \multicolumn{2}{|c|}{ Patients who were working $(n=607)$} & \multicolumn{3}{|c|}{ Patients who were not working $(n=224)$} \\
\hline & & $\begin{array}{c}\text { Factor I } \\
\text { (eigenvalue = 7.46) }\end{array}$ & $\begin{array}{c}\text { Factor II } \\
\text { (eigenvalue }=1.13 \text { ) }\end{array}$ & $\begin{array}{c}\text { Factor I } \\
\text { (eigenvalue }=7.08 \text { ) }\end{array}$ & $\begin{array}{c}\text { Factor II } \\
\text { (eigenvalue = 1.21) }\end{array}$ & $\begin{array}{c}\text { Factor III } \\
\text { (eigenvalue = 1.06) }\end{array}$ \\
\hline \multirow[t]{5}{*}{ Dailyactivities } & 1. House/garden work & .46 & .33 & .51 & .34 & .03 \\
\hline & 2. Different clothes & -.03 & .80 & .17 & .63 & -.06 \\
\hline & 3. Change/wash clothes & .02 & .81 & .04 & .85 & -.05 \\
\hline & 4. Hairdresser problem & -.05 & .79 & .32 & .49 & .01 \\
\hline & 5. More baths & -.11 & .82 & -.30 & .96 & .07 \\
\hline \multirow[t]{5}{*}{ Work } & 6a. Time off work & .83 & -.02 & - & - & - \\
\hline & 7a. Inhibit work & .81 & -.01 & - & - & - \\
\hline & 6b. Less activity & - & - & .83 & .03 & -.05 \\
\hline & 7b. Different activity & - & - & .70 & .18 & -.10 \\
\hline & 8. Career affected & .86 & -.09 & .80 & -.21 & .04 \\
\hline \multirow[t]{2}{*}{ Personalrelations } & 9. Sexual difficulties & .75 & .00 & .87 & -.11 & -.06 \\
\hline & 10. Social relations & .73 & .07 & .81 & -.01 & .00 \\
\hline \multirow[t]{4}{*}{ Leisure } & 11. Social activities & .61 & .23 & .69 & .15 & .01 \\
\hline & 12. Sport difficulties & .55 & .25 & .85 & -.07 & -.05 \\
\hline & 13. Communal changing & .77 & -.11 & .51 & .01 & .41 \\
\hline & 14. More smoke/drink & .62 & -.13 & -.06 & -.00 & .96 \\
\hline Treatment & 15. Home messy/untidy & .60 & .22 & .52 & .14 & .12 \\
\hline
\end{tabular}

Bold values indicate the largest factor loadings for each item.

observed that three factors labeled physical, social, and hygienic disabilities respectively could underlie the disabilities construct in the Norwegian version [35]. Our results confirmed the two factors conception of the PDI for the working patients, one concerning work-related disabilities, the other concerning hygiene and embarrassment, which was consistent with the results obtained in a US sample [32]. For nonworking patients, our results indicated a similar factor structure as those for working patients, which was not consistent with the extraction of one-factor structure in the US sample, however [32]. The differences between present results and the results in the US sample might be partly due to differences in sample characteristics. The multidimensionality of the PDI documented by the existing studies could compromise the validity of the total score of PDI when it is used for measurement of impact of psoriasis.

\section{Strengths and limitations}

This study is important as being the first study to evaluate reliability and validity of the Chinese version of PDI based on a relatively large sample of Chinese patients with psoriasis. The results presented here provide reasonable evidence to show that the Chinese version of PDI has good reliability and validity. There are some limitations, however. Because the PDI was administrated once to the subjects, test-retest reliability, responsiveness to change, and minimal clinical important difference (MCID) were not evaluated. The differential item functioning (DIF) among patients with different demographic variables and cultural background was not evaluated. Enrolled in large hospitals only, the study sample can not be regarded as representative of all Chinese patients with psoriasis. Moreover, there were nearly 30\% sample subjects suffering other chronic disease. The reliability and validity of the PDI in these patients need further studies.

\section{Conclusion}

The Chinese version of PDI is a reliable and valid instrument and can be used to assess patient-reported impact of psoriasis. It is expected to help improve the QOL assessment of Chinese patients with psoriasis because until now there have been few instruments to measure psoriasis-specific QOL in China. The results are comparable to those of the original English version and translated versions in other countries. Therefore, international cooperative research could use the scale to measure QOL in patients with psoriasis.

\section{Competing interests}

The authors declare that they have no competing interest.

\section{Acknowledgements}

We are grateful to Professor Andrew Finlay for permission to use the Chinese version of PDI. This study was funded by the Financial Industry Technology Research and Development Program of Guangdong Province (201105). We thank the investigators of the nine following hospitals: North of China: Beijing Traditional Chinese Medicine Hospital of Capital Medical University, Affiliated Hospital of Liaoning University of Traditional Chinese Medicine; South of China: Guangdong Provincial Hospital of Traditional Chinese Medicine, First Affiliated Hospital of Sun Yat-sen University; East of China: 
Longhua Hospital of Shanghai University of Traditional Chinese Medicine; West of China: Yunnan provincial Hospital of Traditional Chinese Medicine, Teaching Hospital of Chengdu University of Traditional Chinese Medicine, Affiliated Traditional Chinese Medicine Hospital of Xinjiang Medical University; Middle of China: People's Liberation Army 195 Hospital.

\section{Author details}

'Department of Medical Statistics and Epidemiology, School of Public Health, Sun Yat-sen University, 74 ZhongShan Er Road, Guangzhou, 510080, China. ${ }^{2}$ Department of Dermatology, the Second Clinical College, Guangzhou University of Chinese Medicine, Guangzhou, 510120, China. ${ }^{3}$ Department of Clinical Epidemiology, the Second Clinical College, Guangzhou University of Chinese Medicine, Guangzhou, 510120, China.

\section{Author's contributions}

$\mathrm{ZH}$ contributed to the conception and interpretation of the statistical analysis, and drafted the manuscript. CL contributed to the design of the study, training interviewers and drafting the manuscript. AO conducted the statistical analysis, contributed the interpretation of data. JF contributed to the conception and design of the study, and revised the manuscript. DW, JD, $\mathrm{ZZ}$, and JY contributed to the acquisition of data. All authors read and approved the final manuscript

Received: 12 January 2012 Accepted: 13 April 2012

Published: 13 April 2012

\section{References}

1. Griffiths C, Barker JN: Pathogenesis and clinical features of psoriasis. Lancet 2007, 370:263-271

2. Naldi L, Mercuri SR: Epidemiology of comorbidities in psoriasis. Dermatol Ther 2010, 23:114-118.

3. Neimann AL, Shin DB, Wang X, Margolis DJ, Troxel AB, Gelfand JM: Prevalence of cardiovascular risk factors in patients with psoriasis. J Am Acad Dermatol 2006, 55:829-835.

4. Zhang C, Zhu KJ, Zheng HF, Cui Y, Zhou FS, Chen YL, Tang XF, Li M, Zhang FY, Fan X, Zuo XB, Yang S, Sun LD, Zhang XJ: The effect of overweight and obesity on psoriasis patients in Chinese Han population: a hospital-based study. J Eur Acad Dermatol Venereol 2010, 25:87-91.

5. Schmitt JM, Ford DE: Role of depression in quality of life for patients with psoriasis. Dermatology 2007, 215:17-27.

6. Krueger G, Koo J, Lebwohl M, Menter A, Stern RS, Rolstad T: The impact of psoriasis on quality of life: results of a 1998 National Psoriasis Foundation patient-membership survey. Arch Dermatol 2001, 137: 280-284.

7. Stern RS, Nijsten T, Feldman SR, Margolis DJ, Rolstad T: Psoriasis is common, carries a substantial burden even when not extensive, and is associated with widespread treatment dissatisfaction. I Invest Dermatol Symp Proc 2004, 9:136-139.

8. Zachariae R, Zachariae H, Blomqvist K, Davidsson S, Molin L, Mørk C, Sigurgeirsson B: Quality of life in 6479 Nordic patients with psoriasis. Br J Dermatol 2002, 146:1006-1016.

9. Fredriksson T, Pettersson U: Severe psoriasis-oral treatment with a new retinoid. Dermatologica 1978, 157:238-244

10. Krueger GG, Feldman SR, Camisa C, Duvic M, Elder JT, Gottlieb AB, Koo J, Krueger JG, Lebwohl M, Lowe N, Menter A, Morison WL, Prystowsky JH, Shupack JL, Taylor JR, Weinstein GD, Barton TL, Rolstad T, Day RM: Two considerations for patients with psoriasis and their clinicians: What defines mild, moderate, and severe psoriasis? What constitutes a clinically significant improvement when treating psoriasis? J Am Acad Dermatol 2000, 43:281-285.

11. Sampogna F, Sera F, Abeni D: IDI Multipurpose Psoriasis Research on Vital Experiences (IMPROVE) Investigators: Measures of clinical severity, quality of life, and psychological distress in patients with psoriasis: a cluster analysis. J Invest Dermatol 2004, 122:602-607.

12. Chren MM, Weinstock MA: Conceptual issues in measuring the burden of skin diseases. I Invest Dermatol Symp Proc 2004, 9:97-100.

13. Williams HC: Applying trial evidence back to the patient. Arch Dermatol 2003, 139:1195-1200.

14. Finlay AY, Khan GK: Dermatology Life Quality Index (DLQI) - a simple practical measure for routine clinical use. Clin Exp Dermatol 1994, 19: 210-216.
15. Finlay $A Y$, Coles EC: The effect of severe psoriasis on the quality of life of 369 patients. Br J Dermatol 1995, 132:236-244.

16. Chren MM, Lasek RJ, Quinn LM, Mostow EN, Zyzanski SJ: Skindex, a qualityof-life measure for patients with skin disease: reliability, validity, and responsiveness. J Invest Dermatol 1996, 107:707-713.

17. Morgan M, McCreedy R, Simpson J, Hay RJ: Dermatology Quality of Life Scales-a measure of the impact of skin disease. Br J Dermatol 1997 136:202-206.

18. McKenna SP, Cook SA, Whalley D, Doward LC, Richards HL, Griffiths CE, Van Assche D: Development of the PSORIQoL, a psoriasis-specific measure of quality of life designed for use in clinical practice and trials. Br J Dermatol 2003, 149:323-331.

19. Ashcroft DM, Li Wan Po A, Williams HC, Griffiths CE: Quality of life measures in psoriasis: A critical appraisal of their quality. $J$ Clin Pharm Ther 1998, 23:391-398.

20. Both H, Essink-Bot ML, Busschbach J, Nijsten T: Critical review of generic and dermatology-specific health-related quality of life instruments. J Invest Dermatol 2007, 127:2726-2739.

21. Bronsard V, Paul C, Prey S, Puzenat E, Gourraud PA, Aractingi S, Aubin F, Bagot M, Cribier B, Joly P, Jullien D, Le Maitre M, Richard-Lallemand MA, Ortonne JP: What are the best outcome measures for assessing quality of life in plaque type psoriasis? A systematic review of the literature. J Eur Acad Dermatol Venereol 2010, 24:17-22.

22. Chren MM: Understanding research about quality of life and other health outcomes. J Cutan Med Surg 1999, 3:312-316.

23. Lewis VJ, Finlay AY: Two decades experience of the psoriasis disability index. Dermatology 2004, 210:261-268.

24. Shek D, Chan Y, Lee P: Quality of life in the global context: a chinese response. Soc Indic Res 2005, 71:1-10.

25. Basra MKA, Fenech R, Gatt RM, Salek MS, Finlay AY: The Dermatology Life Quality Index 1994-2007: a comprehensive review of validation data and clinical results. Br J Dermatol 2008, 159:997-1035.

26. Department of Dermatology and Wound Healing of Cardiff University: Quality of Life \& Dermatology Life Quality Index. Available at: http://www. dermatology.org.uk (last accessed 28 October 2010)

27. He Z, Lu C, Basra MKA, Ou A, Yan Y, Li L: Psychometric properties of the Chinese version of Dermatology Life Quality Index (DLQI) in 851 Chinese patients with psoriasis. J Eur Acad Dermatol Venereol 2011. doi:10.1111/ j.1468-3083.2011.04371.x.

28. Ware JE, Snow KK, Kosinski MK, Gandek B: SF-36 Health Survey: Manual and Interpretation Guide. Boston: The Health Institute, New England Medical Center; 1993.

29. Li L, Wang HM, Shen Y: Chinese SF-36 health survey: translation, cultural adaptation, validation, and normalisation. J Epidemiol Community Health 2003, 57:259-263.

30. Schmitt J, Wozel G: The psoriasis area and severity index is the adequate criterion to define severity in chronic plaque-type psoriasis. Dermatology 2005, 210:194-199.

31. Anderson RT, Rajagopalan R: Development and validation of a quality of life instrument for cutaneous diseases. J Am Acad Dermatol 1997, 37:41-50.

32. Nijsten T, Whalley D, Gelfand J, Margolis D, McKenna SP, Stern RS: The psychometric properties of the psoriasis disability index in United States patients. J Invest Dermatol 2005, 125:665-672.

33. Abramson JH: Survey methods in community medicine. Edinburgh: Churchill Livingstone; 1990.

34. Colton T: Statistics in medicine. Boston: Little, Brown; 1974.

35. Wahl AK, Wiklund I, Moum T, Hanestad BR: The norwegian version of the psoriasis disability index-a validation and reliability study. Value Health 1999, 2:342-349.

36. Aghaei S, Moradi A, Ardekani GS: Impact of psoriasis on quality of life in Iran. Indian I Dermatol Venereol Leprol 2009, 75:220

37. Kent $\mathrm{G}$, al Abadie M: The Psoriasis Disability Index-further analyses. Clin Exp Dermatol 1993, 18:414-416.

\section{doi:10.1186/1477-7525-10-37}

Cite this article as: He et al:: Reliability and validity of the Chinese version of the Psoriasis Disability Index (PDI) in Chinese patients with psoriasis. Health and Quality of Life Outcomes 2012 10:37. 